\title{
Editorial
}

\section{Afinal, o que se busca é comparabilidade ou uniformidade?}

\author{
Raquel Wille Sarquis \\ raquel.sarquis@usp.br \\ Doutora em Controladoria e Contabilidade pela Universidade de São Paulo (FEA/USP) \\ Professora no Departamento de Contabilidade e Atuária da Faculdade de Economia, Administração e Contabilidade da Universidade de São Paulo
}

\section{INTRODUÇÃO}

A Estrutura Conceitual define que para as informações contábeis serem úteis, elas precisam ser relevantes e representar fidedignamente aquilo que pretendem representar. A comparabilidade, por sua vez, é uma característica qualitativa que aumenta a utilidade da informação contábil, ao permitir que os usuários identifiquem e compreendam as similaridades e diferenças entre os itens. Tarca (2020) argumenta que as informações de uma empresa serão mais úteis se puderem ser comparadas com as informações de outra empresa ou com informações da mesma empresa em outro período.

Toda decisão de investimento envolve a escolha entre alternativas. É nesse contexto que Barth (2013) defende que se o objetivo da divulgação de informações contábeis é fornecer aos investidores, credores e demais usuários que os ajudem no processo de tomada de decisão sobre a alocação de recursos, a comparabilidade é uma característica crucial da informação contábil. Se os usuários das informações contábeis não puderem comparar oportunidades alternativas de investimento, as suas decisões de alocação de recursos serão ineficientes (Barth 2013).

Barth (2013) também menciona que é difícil imaginar como a comparabilidade poderia ser atingida sem a adoção global de um padrão contábil único, principalmente quando o objetivo é comparar empresas de países diferentes. Consequentemente, o aumento da comparabilidade é um dos principais argumentos utilizados pelos defensores da adoção global das normas Internatinal Financial Reporting Standards (IFRS), emitidas pelo International Accounting Standards Board (IASB) (Tarca, 2020).

Entretanto, comparabilidade não é algo diretamente observável e, portanto, não é um conceito de fácil entendimento e mensuração. Afinal, como saber se duas informações são ou não comparáveis? Qual o nível de comparabilidade? São comparáveis sob qual perspectiva? Talvez por conta disso é que o conceito de comparabilidade é muito mal-interpretado na prática, tanto pelos usuários das informações contábeis quanto pelas próprias pesquisas acadêmicas.

Barth (2013) menciona que o conceito de comparabilidade é muitas vezes confundido com uniformidade, sendo que são dois conceitos completamente diferentes. Enquanto o conceito de comparabilidade é voltado para o reflexo da substância econômica dos eventos, fazendo com que coisas semelhantes pareçam semelhantes e coisas diferentes pareçam diferentes, a uniformidade pode prejudicar a comparabilidade ao fazer com que coisas diferentes pareçam iguais (Tarca, 2020).

Existe quase que consenso entre os usuários das informações contábeis que quando duas empresas utilizam práticas contábeis diferentes elas são necessariamente menos comparáveis. Essa visão é uma consequência do entendimento inadequado do conceito de comparabilidade, já que a utilização da mesma prática contábil por todas as empresas pode resultar em maior uniformidade, mas não necessariamente em maior comparabilidade. Essa confusão de conceitos também é observada nas pesquisas acadêmias, já que muitos trabalhos dizem mensurar a comparabilidade, mas na verdade utilizam como métrica a uniformidade, já que mensuram pela quantidade de empresas que utilizam a mesma prática contábil.

Portanto, o objetivo deste editorial é discutir os conceitos de comparabilidade e uniformidade e suas diferenças, principalmente no âmbito do processo global de adoção de um padrão contábil único. Especificamente, tem-se o propósito de chamar a atenção do leitor para o fato de que as informações contábeis precisam ser comparáveis (essência econômica), mas não necessariamente uniformes (forma jurídica).

\section{CONCEITOS DE COMPARABILIDADE E UNIFORMIDADE}

Comparabilidade é um conceito abstrato, não diretamente observável, sendo difícil avaliar quando duas coisas são comparáveis e quando não são (Gordon \& Gallery, 2012, Zeff, 2007). O que sabemos, entretanto, é que o conceito de comparabilidade é baseado no reflexo da substância econômica dos eventos e não na forma jurídica (Simmons, 1967).

A Estrutura Conceitual define comparabilidade como sendo uma característica qualitativa da informação contábil, que "permite aos usuários identificar e compreender similaridades e diferenças entre itens" (CPC 00 (R2), 2019, item 2.25). Nesse sentido, a literatura sobre comparabilidade das informações contábeis defende que comparabilidade existe quando os usuários das informações contábeis são capazes de distinguir similaridades e diferenças na substância econômica dos eventos de uma mesma entidade ao longo do tempo e entre entidades diferentes (Barth, 2013; Barth, Lands- 
man, Lang, \& Willians, 2018; Barth, Landsman, Lang, \& Williams, 2012; Brochet, Jagolinzer, \& Riedl, 2013; De Franco, Kothari, \& Verdi, 2011; DeFond, Hu, Hung, \& Li, 2011; Gordon \& Gallery, 2012, Ribeiro, 2014, Yip \& Young, 2012).

Dessa definição, dois aspectos importantes merecem atenção. O primeiro é que a comparabilidade pode ser avaliada em uma mesma entidade ao longo do tempo ou entre entidades diferentes. Fato é que atingir a comparabilidade entre empresas localizadas em países diferentes é muito mais complexo do que atingir a comparabilidade entre empresas de um mesmo país ou em uma mesma empresa ao longo do tempo, já que as empresas não estão no mesmo ambiente institucional, cultural e regulatório (Zeff, 2007).

O segundo aspecto é que o conceito de comparabilidade deve ser analisado sob duas abordagens diferentes: a da similaridade e a das diferenças (Gordon \& Gallery, 2012; Liao, Sellhorn, \& Skaife, 2012; Yip \& Young, 2012). Pela abordagem da similaridade, a comparabilidade é atingida quando eventos econômicos similares são reconhecidos utilizando práticas contábeis semelhantes. Pela abordagem das diferenças, a comparabilidade é atingida quando práticas contábeis diferentes são utilizadas para reconhecer eventos econômicos diferentes. A comparabilidade global somente será atingida quando as duas abordagens forem levadas em consideração.

Da mesma forma que a utilização de práticas diferentes para reconhecimento do mesmo evento econômica prejudica a comparabilidade, a utilização da mesma prática contábil para reconhecimento de eventos econômicos diferentes também não permite que a comparabilidade genuína das informações contábeis seja atingida. O item 2.27 da própria Estrutura Conceitual alerta para o fato de que a comparabilidade não é atingida fazendo-se que coisas diferentes pareçam semelhantes.

É nesse contexto que Barth (2013) ressalta a importância de distinguir os conceitos de comparabilidade e uniformidade, que apesar de apresentarem certa relação, são essencialmente diferentes, já que comparabilidade não é atingida com uniformidade. Pelo contrário, a uniformidade pode prejudicar a comparabilidade fazendo com que coisas diferentes sejam tratadas da mesma forma (Barth, 2013; Gordon \& Gallery, 2012). Enquanto a comparabilidade significa tratar coisas semelhantes de forma semelhante e coisas diferentes de forma diferente, a uniformidade significa tratar todas as coisas da mesma forma. Observa-se, portanto, que enquanto o conceito de comparabilidade busca refletir a essência econômica, o conceito de uniformidade é muito mais voltado para a forma jurídica do evento.

Para ilustrar como a utilização de práticas contábeis uniformes pode prejudicar a comparabilidade genuína das informações contábeis, vale mencionar como exemplo a definição da vida útil dos ativos e o método de depreciação. A obrigatoriedade de que todas as empresas depreciem seus edifícios, por exemplo, em 25 anos e de forma linear somente resultará em comparabilidade se todas as empresas consumirem os benefícios econômicos desse ativo exatamente da mesma forma. Se a vida útil desse edifício for diferente entre as empresas, ou ainda, se a forma de consumo dos benefícios econômicos desse ativo for diferente, a utilização da mesma prática contábil de depreciação resultará apenas em uniformidade, mas não em comparabilidade, já que fará com que todos os edifícios pareçam semelhantes quando na verdade são diferentes (Barth, 2013).

\section{REGULAÇÃO CONTÁBIL BASEADA EM REGRAS OU EM PRINCÍPIOS}

Não existem dúvidas sobre a necessidade da existência de regulação contábil (Scott, 2015; Watts \& Zimmerman, 1986). A questão que permance em aberto, entretanto, é o nível de detalhamento e especificidade que deve existir nas normas contábeis. Ou seja, se a regulação contábil deveria ser conduzida por meio de regras ou de princípios.

De um lado, os padrões contábeis baseados em regras são aqueles em que as normas contábeis fornecem um conjunto extenso de regras bastante detalhadas e específicas para o maior número possível de transações, além de exemplos e guias de implementação especificando o tratamento contábil que deve ser utilizado em cada situação. Do lado oposto, padrões contábeis baseados em princípios são aqueles em que as normas contábeis fornecem um conjunto de princípios fundamentais, que devem ser utilizados pelos preparadores das informações contábeis no exercício do seu julgamento profissional sobre qual tratamento contábil é mais adequado em cada situação (Carmona \& Trombeta, 2008; Kothari, Ramanna, \& Skinner, 2010; Nelson, 2003, Psaros \& Trotman, 2004).

Nesse sentido, Kothari et al. (2010) argumentam que essa discussão sobre padrões contábeis baseados em regras ou em princípios na verdade é uma discussão sobre os custos e benefícios de se deixar a cargo do julgamento profissional dos preparadores das informações contábeis um número maior ou menor de escolhas contábeis. Nos padrões contábeis baseados em regras, as normas contábeis especificam exatamente qual tratamento contábil deve ser utilizado em cada transação, cabendo ao preparador da informação contábil simplesmente aplicar o que está previsto na norma. Já nos padrões contábeis baseados em princípios, as normas contábeis demandam dos preparadores das informações contábeis o exercício de julgamento profissional para determinar qual tratamento contábil deve ser utilizado.

Observa-se, portanto, que a adoção de padrões contábeis baseados em regras está muito mais voltado para o conceito de uniformidade do que comparabilidade das informações contábeis, já que o preparador da informação contábil deve simplesmente aplicar o que está previsto na norma, sem considerar a essência econômica da transação e o ambiente em que a empresa está inserida. Os padrões contábeis baseados em princípios, por sua vez, estão mais relacionados com o conceito de comparabilidade, já que deixam a cargo do julgamento profissional do preparador da informação contábil a definição de qual prática contábil melhor reflete a essência econômica da transação.

A principal crítica ao modelo de regulação contábil baseada em princípios é que esse aumento no poder discricionário dos preparadores das informações contábeis pode resultar em maior nível de gerenciamento de resultados, já que 
eles podem escolher a prática contábil que melhor atenda aos seus interesses e não aquela que melhor reflete a essência econômica da transação (Bratton, 2003; Hope, 2004). Apesar de válida, essa crítica é bastante questionável, já que padrões contábeis baseados em regras bastante específicas também fornecem incentivos para os gestores estruturarem transações que atendam determinadas regras que estejam alinhadas aos seus interesses, o que também é uma forma de gerenciamento de resultados.

Por fim, vale ressaltar que padrões contábeis baseados em princípios não significam que os preparadores das informações contábeis podem escolher de forma livre e arbitrária a prática contábil que desejam utilizar, pois existe um conjunto de princípios contábeis claramente definidos que devem ser utilizados como direcionadores no exercício do julgamento profissional. Tais princípios, se adequadamente elaborados e aplicados, devem reduzir o comportamento oportunista do preparador da informação contábil e, portanto, resultar em informações contábeis mais relevantes e mais comparáveis do que padrões contábeis baseados em regras.

\section{ADOÇÃO DAS NORMAS INTERNACIONAIS DE CONTABILIDADE}

A discussão sobre a necessidade e importância da comparabilidade das informações financeiras ganhou ainda mais destaque com o processo de convergência para as normas internacionais de contabilidade, já que o aumento da comparabilidade (principalmente entre países diferentes) é um dos principais argumentos utilizados pelos defensores da adoção global de um padrão contábil único (Tarca, 2020).

Nesse sentido, as normas internacionais de contabilidade (IFRS) emitidas pelo IASB têm recebido aceitação global. Especificamente, das 166 jurisdições analisadas pela Fundação IFRS, 144 (87\%) requerem a adoção obrigatória das IFRS para todas ou quase todas as suas empresas de capital aberto. E essa grande aceitação é digna de aplausos. Elaborar um padrão contábil único que possa ser aplicado em países com ambientes culturais e institucionais diferentes não é uma tarefa fácil. Conforme Zeff (2012), obter a comparabilidade entre empresas de países diferentes é muito mais difícil do que obter a comparabilidade entre empresas de um mesmo país, já que o ambiente cultural e institucional é diferente. A forma como os negócios são conduzidos na Coréia do Sul é diferente das Filipinas, do Sri Lanka, da Rússia, do Brasil e do Canadá, por exemplo.

Existe uma literatura bastante rica que sugere que a contabilidade, como uma ciência social, é fortemente influenciada pelo ambiente em que está inserida. Portanto, as características do ambiente cultural e institucional de cada país (como herança cultural, sistema legal, nível de desenvolvimento econômico, nível de enforcement, forma de financiamento das empresas, sistema político, idioma, religião, etc.) podem afetar o desenvolvimento da contabilidade (Doupnik \& Salter, 1995; Gray, 1988; Hofstede, 1980; La Porta, Lopez-de-Silanes, Shleifer, \& Vishny, 1998; Leuz, 2010; Nobes, 1998; Nobes \& Parker, 2012; Weffort, 2003).

O objetivo da Fundação IFRS é emitir um conjunto único de normas contábeis de elevada qualidade e que sejam baseadas em princípios claramente definidos. Para Carmona e Trombetta (2008), a principal diferença entre as IFRS e a maioria dos padrões contábeis locais que existiam até então é justamente essa característica principiológica das IFRS. E foi justamente por serem normas contábeis baseadas em princípios (e não em regras) que as IFRS tiveram essa aceitação global e puderam ser aplicadas em países com ambientes culturais e institucionais diferentes.

Sendo normas contábeis baseadas em princípios, as IFRS permitem maior liberdade para que os preparadores das informações contábeis exerçam seu julgamento profissional na definição de qual tratamento contábil melhor reflete a essência econômica da operação, considerando o ambiente em que estão inseridos. Tanto por essa abordagem principiológica quanto com a finalidade de atrair mais simpatizantes, as primeiras normas emitidas pelo IASC (órgão predecessor do IASB) permitiam uma quantidade maior de escolhas contábeis (Martins, Martins, \& Martins, 2007; Zeff, 2012). Entretanto, mais recentemente o IASB tem adotado uma postura de eliminar escolhas contábeis sempre que possível, com o argumento de que a existência de tais escolhas prejudica a comparabilidade das informações contábeis. Esse posicionamento está bastante explícitio no Preface to IFRS Standards (Red Book), quando o IASB menciona que tem reavaliado as transações e eventos em que as IFRS permitem opções de tratamentos contábeis, com o objetivo de eliminar o maior número possível de escolhas contábeis.

Aqui precisamos de um pouco de cuidado. Se por um lado esse objetivo de eliminar escolhas sempre que possivel visando aumentar a comparabilidade pode fazer sentido, já que previne que as empresas utilizem tratamentos contábeis distintos para o mesmo evento econômico, por outro lado também pode forçar eventos economicamente diferentes a serem reconhecidos da mesma forma. Isso, consequentemente, aumenta a uniformidade mas não a comparabilidade. Nesse sentido, um pouco de cautela é necessária por parte do regulador na avaliação sobre se determinada escolha contábil deve ser permitida ou não.

Ao adotar uma postura de eliminação de escolhas contábeis sempre que possível, o IASB pode estar se afastando do seu propósito de ser um padrão contábil baseado em princípios e isso poderia limitar a sua aplicabilidade em países com ambientes culturais e institucionais diferentes. Nesse sentido, vale mencionar a citação de Richard Breeden (1992), ex-presidente da SEC: "Common global standard, if read to mean identifical, is na illusory and unobtainable goal. However, seeking to achieve similar objectives and to adress in an effective way similar problemas is a realistic goal" (Sunder, 2010, p.100). 


\section{COMENTÁRIOS FINAIS}

A representação fidedigna é uma das características fundamentais das informações contábeis. A uniformização das práticas contábeis pode fazer com que coisas diferentes sejam tratadas da mesma forma e isso, consequentemente, faz com que a informação contábil produzida não represente de forma fidedigna o evento econômico que pretende representar. Sendo assim, a busca deve ser por informações contábeis comparáveis, que reflitam as similaridades e diferenças nos eventos econômicos, mas não necessariamente uniformes.

É nesse contexto que um dos principais desafios do IASB, como órgão responsável pela emissão de normas contábeis que são aplicadas em países com ambientes culturais e institucionais bastante diferentes, é justamente definir qual o nível de flexibilidade que deve ser permitido aos preparadores das informações contábeis no exercício do seu julgamento profissional para que a comparabilidade global possa ser atingida. Zeff (2012) argumenta que o IASB precisa tomar suas decisões com sabedoria e sempre buscando promover a comparabildiade global genuína das informações contábeis, o que pode demandar sim a existência de tratamentos contábeis opcionais em decorrência de particularidades nos ambientes culturais e instituconais de cada país.

A academia exerce um papel fundamental nesse processo, ao desenvolver pesquisas que busquem avaliar os efeitos dessa maior ou menor flexibilização na comparabilidade das informações contábeis. Nesse sentido, um dos principais desafios da academia é propor e testar métricas que busquem mensurar de forma mais fidedigna o conceito de comparabilidade (ao invés de uniformidade). Já existem alguns trabalhos nesse sentido (Barth et al., 2012; De Franco et al., 2011; Yip \& Young, 2012), que buscam relacionar os sistemas contábeis com variáveis de mercado, mas essas métricas possuem aplicação limitada quando o objetivo é avaliar normas contábeis específicas.

\section{REFERÊNCIAS}

Barth, M. E. (2013). Global comparability in financial reporting: What, why, how, and when? China Journal of Accounting Studies, 1(1), 2-12.

Barth, M. E., Landsman, W. R., Lang, M. H. \& Williams, C. D. (2018). Effects on comparability and capital markets benefits of voluntary IFRS adoption. Journal of Financial Reporting, 3 (1), 1-22.

Barth, M. E., Landsman, W. R., Lang, M. \&Willians, C. (2012). Are IFRS-based and US GAAP-based accounting amounts comparable? Journal of Accounting and Economics, 54 (1), 68-93.

Bratton, W. W. (2003). Enron, Sarbanes-Oxley and accounting: Rules versus principles versus rents. Villanova Law Review, 48 (4), 1023.

Brochet, F., Jagolinzer, A. D. \& Riedl, E. J. (2013). Mandatory IFRS adoption and financial statement comparability. Contemporary Accounting Research, 30 (4), 1373-1400.

Carmona, S. \& Trombetta, M. (2008). On the global acceptance of IAS/IFRS accounting standards: The logic and implications of the principles-based system. Journal of Accounting and Public Policy, 27(6), 455-461.

CPC 00 (R2). (2019). Estrutura Conceitual para Relatório Financeiro. CPC - Comitê de Pronunciamentos Contábeis. Recuperado de http://static.cpc.aatb.com.br/Documentos/573_CPC00(R2).pdf

De Franco, G., Kothari, S. \& Verdi, R. S. (2011). The benefits of financial statements comparability. Journal of Accounting Research, 49(4), 895-931.

DeFond, M., Hu, X., Hung, M. \& Li, S. (2011). The impact of mandatory IFRS adoption on foreign mutual fund ownership: The role of comparability. Journal of Accounting and Economics, 51(3), 240-258.

Doupnik, T. S. \& Riccio, E. L. (2006). The influence of conservatism and secrecy on the interpretation of verbal probability expression in the Anglo and Latin cultural areas. The International Journal of Accounting, 41(3), 237-261.

Gordon, I. \& Gallery, N. (2012). Assessing financial reporting comparability across institutional settings: The case of pension accounting. The British Accounting Review, 44(1), 11-20.

Gray, S. J. (1980). The impact of international accounting differences from a security-analysis perspective: some European evidence. Journal of Accounting Research, 64-76.

Hofstede, G. (1980). Culture's consequences. Sage.

Hope, O. K. (2004). Variations in the financial reporting environment and earnings forecasting. Journal of International Financial Management \& Accounting, 15(1), 21-43.

Kothari, S., Ramanna, K. \& Skinner, D. J. (2010). Implications for GAAP from an analisys of positive research in accounting. Journal of Accounting and Economics, 50(2), 246-286.

La Porta, R., Lopez-de-Silanes, F., Shleifer, A. \& Vishny, R. (1998). Law and Finance. Journal of Political Economy, 106(6), 1113-1155.

Leuz, C. (2010). Different approaches to corporate reporting regulation: How jurisdictions differ and why. Accounting and Business Research, 40(3), 229-256.

Liao, Q., Sellhorn, T. \& Skaife, H. A. (2012). The cross-country comparability of IFRS earnings and book values: Evidence from France and Germany. Journal of International Accounting Research, 11(1), 155-184. 
Nelson, M. W. (2003). Behavioral evidence on the effects of principles-and rules-based standards. Accounting Horizons, 17(1), 91-104.

Nobes, C. (1998). Towards a general model of the reasons for international differences in financial reporting. Abacus, 34(2), $162-187$.

Nobes, C. \& Parker, R. B. (2012). Comparative international accounting (12a ed.). Harlow: Prentice Hall.

Martins, E., Martins, V. A., \& Martins, É. A. (2007). Normatização contábil: ensaio sobre sua evolução e o papel do CPC. Revista de Informação Contábil, 1(1), 7-30.

Psaros, J. \& Trotman, K. T. (2004). The impact of the type of accounting standards on preparers' judgment. Abacus, 40(1), 76-93.

Ribeiro, A. M. (2014). Poder discricionário do gestor e a comparabilidade dos relatórios financeiros: Uma análise do efeito da convergência do Brasil às IFRS (tese de doutorado, Faculdade de Economia, Administração e Contabilidade da Universidade de São Paulo - FEA/ USP, São Paulo).

Scott, W. R. (2015). Financial Accounting Theory (7a ed.). Nova Jersey: Prentice Hall.

Simmons, J. K. (1967). A concept of comparability in financial reporting. The Accounting Review, 42(4), 680-692.

Sunder, S. (2010). Adverse effects of uniform written reporting standards on accounting practice, education, and research. Journal of Accounting and Public Policy, 29(2), 99-114.

Tarca, A. (2020). The IASB and comparability of international financial reporting: Research evidence and implications. Australian Accounting Review, 30(4), 231-242.

Watts, R. L. \& Zimmerman, J. L. (1986). Positive Accounting Theory. Prentice-Hall Inc.

Weffort, E. F. J. (2003). O Brasil e a harmonização contábil internacional: influências dos sistemas jurídico e educacional, da cultura e do mercado (tese de doutorado, Faculdade de Economia, Administração e Contabilidade da Universidade de São Paulo - FEA/USP, São Paulo).

Yip, R. W. \& Young, D. (2012). Does mandatory IFRS adoption improve information comparability? The Accounting Review, 87(5), 1767-1789.

Zeff, S. A. (2007). Some obstacles to global financial reporting comparability and convergence at a high level of quality. The British Accounting Review, 39(4), 290-302.

Zeff, S. A. (2012). The evolution of the IASC into the IASB, and the challenges it faces. The Accounting Review, 87(3), 807-837. 